\title{
gifoRSETI
}

Forseti. Revista de Derecho. Volumen 7, № 10, Lima, 2019, pp. 42 - 54

\section{Apuntes sobre la caducidad y la seguridad jurídica}

\author{
Roxana Jiménez Vargas-Machuca*
}

Resumen. - En el presente artículo, la autora se pronuncia sobre la seguridad jurídica, institución que permite que el equilibrio de los intereses sociales e individuales en el Derecho. Asimismo, se refiere a la seguridad jurídica como fundamento de la caducidad. De esta manera, reflexiona sobre actualizaciones respecto del alcance de la caducidad en supuestos específicos.

\begin{abstract}
The author refers to legal security as an institution that allows law to balance individual and social interests. In addition, she describes legal security as expiration's main basis and mentions updates on its effectiveness in specific cases.
\end{abstract}

Palabras claves. - Seguridad jurídica; caducidad; intereses individuales y sociales; actualización; arbitraje.

Keywords. - Legal security; expiration; individual and social interests; update; arbitration.

* Árbitro en diversas instituciones arbitrales (PUCP, AMCHAM, OSCE, entre otros). Abogada por la Pontificia Universidad Católica del Perú. Maestría culminada en la Pontificia Universidad Católica del Perú y doctorado culminado en la Universidad Nacional Mayor de San Marcos. Se ha desempeñado como profesora de pregrado en la materia de Derecho Civil en la Universidad de Lima y ESAN, y como profesora de posgrado en la Universidad de Piura. 


\section{Seguridad jurídica y ordenamiento jurídico}

Para el ser humano el conocimiento acerca de qué conductas o acciones de otros pueden interferir en las suyas o en sus intereses, y viceversa, siempre ha sido preponderante. Ciertamente, es característico de la condición humana querer saber a qué atenerse en la relación con los demás, por lo que no solo requiere "saber a qué atenerse sobre lo que debe ocurrir, sino necesita también saber que esto ocurrirá necesariamente; esto es, precisa de certeza sobre las relaciones sociales, pero además de la seguridad de que la regla se cumplirá, de que estará poderosamente garantizada" 1 .

Como especie del género seguridad, la seguridad jurídica se entiende como la seguridad proporcionada por el Derecho (entendiendo Derecho como orden jurídico), lo cual implica la afirmación del ordenamiento aun contra los intereses individuales. Es así que una sociedad organizada requiere de un grado mínimo de predictibilidad entre sus unidades sociales respecto de lo que cada una puede esperar de las otras; por ello, la predictibilidad es el eje de la seguridad. La seguridad jurídica da coherencia y capacidad moral de coerción a la norma jurídica.

De modo preliminar, suele reducirse el ámbito de la seguridad jurídica a un esquema como el siguiente:

- Que el sistema haya sido regularmente establecido en términos iguales para todos.

- Que este sistema se base en leyes susceptibles de ser conocidas por todos. En este punto resulta evidente la importancia de la información.

- Que estas leyes se apliquen a conductas posteriores (no anteriores) a su vigencia para que no se produzcan cambios de las reglas de juego en que se contrató o se invirtió, esto es, que se respeten los derechos adquiridos.

- Que las leyes sean claras y no confusas o ambiguas.

- Que las leyes sean dictadas adecuadamente por quien está investido de facultades para hacerlo. Dentro de esta característica se encuentra implícita la eficacia de los mecanismos de aplicación del Derecho.

- Que el Derecho positivo no se encuentre expuesto a cambios demasiado frecuentes, es decir, que no se halle a merced de una legislación incidental. Esto involucra una estabilidad del orden jurídico.

Empero, siendo función del Derecho regular la convivencia humana, la seguridad jurídica afirma la certeza y la permanencia de las situaciones jurídicas dentro de un ordenamiento jurídico establecido, cuya herramienta es la legalidad (para qué la

1 RECASENS SICHES, Luis. Vida Humana, Sociedad y Derecho. Fundamentación de la Filosofía del Derecho. México: Fondo de Cultura Económica, 1945, p. 210. 
legalidad si no es para brindar seguridad jurídica), entendida (la legalidad), eso sí, en un contexto de legitimidad, a fin de no perder sentido y quedar como un cuerpo sin alma, que devenga en incapaz de proporcionar seguridad jurídica: la legitimidad se encuentra relacionada con la validez social de la norma, fundamento necesario de la legalidad, orientado a valores socialmente aceptados (como la justicia).

Entonces, la certeza y la seguridad, aunque constituyen una finalidad para el Derecho (para Recasens Siches la seguridad es el sentido formal de la función del Derecho'), no son suficientes, puesto que las normas que las proporcionan no deben ser apreciadas como injustas.

Cierto es que la deficiente gestión que genera caos, produce un nivel de inseguridad jurídica (por ejemplo, cuando se da una elevada producción cuantitativa de leyes, muchas de las cuales tienen por objeto modificar o derogar total o parcialmente leyes anteriores, siendo aquellas, a su vez, modificadas por otras posteriores, siendo tales modificaciones realizadas a veces de modo expreso y a menudo de modo tácito, lo cual conlleva dudas respecto de la vigencia de un texto legal determinado, generando error en privados y en instituciones públicas), pero no es este desorden el problema central que deriva de la inseguridad jurídica proveniente de un ordenamiento jurídico inseguro en su estructura, esto es, de un ordenamiento jurídico irracional, que yuxtapone valores contradictorios entre sí, encadenando la realidad dentro de un esquema rígido de normas lineales que ya no le corresponden. ${ }^{3}$

Es necesario entender que no es la norma jurídica la que proporciona o resta seguridad jurídica a la sociedad sino el ordenamiento como tal; la norma jurídica debe apreciarse en su participación organizada en un conjunto (orden jurídico). Como señala Rómulo Morales Hervias, no son las normas las que crean el orden jurídico sino, por el contrario, es el orden jurídico el que se organiza en normas, habiendo surgido como respuesta a las necesidades sociales y económicas de una determinada sociedad.

Es, pues, fundamental tener una estructura definida y coherente para luego analizar sus partes. Por ello, el mero análisis de la norma jurídica aislada no brinda la idea adecuada del orden jurídico en su conjunto y de sus objetivos y propósitos sociales, por lo que la idea de lo que es Derecho resultaría incompleta 4 .

En este sentido, el Derecho no es -no debe ser- un conjunto de caprichos

2 Ibid., pp. 210-211. Este mismo autor opina que el derecho no surge como ejercicio de devoción a valores tales como la justicia, sino "al impulso de una urgencia de seguridad" (p. 209).

3 JIMÉNEZ VARGAS-MACHUCA, Roxana. "La seguridad jurídica como un valor orientador del derecho" En JUS, Doctrina \& Práctica, núm. 5, mayo 2007. Publicación especializada y actualizada para el profesional del Derecho. Lima: Editorial Grijley.

4 Fernando de Trazegnies hace una analogía bastante gráfica de lo que significaría analizar en forma aislada a las normas jurídicas con el estudio de un edificio a través de sus ladrillos. Cfr. DE TRAZEGNIES GRANDA, Fernando. Filosofía del Derecho. Materiales de Enseñanza. Pontificia Universidad Católica del Perú, Lima, 1982. 
imperativos o de voluntades arbitrarias del legislador, sino un sistema ordenado que permite tanto el juego de los intereses individuales como de los sociales. El aggiornamento de las figuras e instituciones jurídicas es indispensable, y es labor de la doctrina y, más aún, de la jurisprudencia.

\section{La caducidad}

El rol esencial de la caducidad se asienta en la seguridad jurídica.

De acuerdo a la normativa, por la caducidad se extingue, por el transcurso del tiempo, el derecho y la acción. Ahora bien, en este punto es relevante referirse a la opinión de la doctrina nacional autorizada, para la cual tanto la prescripción como la caducidad son mecanismos extintivos de situaciones jurídicas subjetivas: el objeto de ambas instituciones es la entera relación jurídica lo que incluye las situaciones jurídicas subjetivas activas y pasivas que la conforman (no es la acción, la pretensión, ni el derecho, como se encuentra redactado en el Código Civil) ${ }^{5}$, por lo que la distinción entre ambas radica en su operatividad.

El legislador ha establecido un término fatal para que se inicien los procesos correspondientes, vencido el cual no podrán incoarse ${ }^{6}$. El fundamento de la figura se halla en la necesidad por parte del conglomerado social de obtener seguridad jurídica para evitar la paralización del tráfico jurídico; en esta medida, la caducidad no protege ni concede derechos subjetivos, sino que apunta a la protección de un interés general.

En efecto, la caducidad se rige por normas imperativas, forma parte del derecho público por existir en su concepción un ingrediente de interés público, por lo que se encuentra de medio el orden público; sus eventualidades y causales están expresa y taxativamente establecidas en la ley, con preceptos rígidos que no admiten disponibilidad.

A diferencia de la prescripción -que tiene base de autonomía, al ser disponible, por lo que debe ser alegada en excepción procesal por la parte demandada-, la caducidad opera ipso iure, no encontrándose en poder de nadie el disponer de ella bajo alguna forma o modalidad. Es así que la prescripción otorga la posibilidad al deudor de liberarse, la que puede o no aprovechar, de acuerdo a su voluntad. ${ }^{7}$

En esa línea, la norma establece que la caducidad se produce transcurrido el último día del plazo, aunque esta sea inhábil ${ }^{8}$ (a diferencia de la prescripción, sobre cuyo vencimiento la norma solamente señala que se produce vencido el último día del plazo, lo que implica que se trata de día hábil), y esto remarca la indefectibilidad

5 ARIANO DEHO, Eugenia. “Reflexiones sobre la prescripción y la caducidad a los treinta años de vigencia del Código Civil". En Themis, núm. 66, 2014, p. 330.

6 Artículo 2004 del Código Civil del Perú.- Legalidad en plazos de caducidad Los plazos de caducidad los fija la ley, sin admitir pacto contrario.

7 ARIANO DEHO, Op. cit., p. 334.

8 Artículo 2007 del Código Civil del Perú.- Cumplimiento del plazo de caducidad La caducidad se produce transcurrido el último día del plazo, aunque éste sea inhábil. 
de su acaecer, resultando independiente y ajeno a la voluntad de las personas.

En ese sentido, se ha señalado que "la diferencia fundamental entre prescripción y caducidad es que mientras en el primero es necesaria la actuación del derecho potestativo del beneficiario (en vía de excepción o de acción), en fin, la actuación de su autonomía privada; en el segundo, se trata de un fenómeno de extinción heterónoma de las situaciones jurídicas subjetivas, es decir, se prescinde totalmente de la intención, voluntad y actuación del beneficiado con el plazo" 9 .

La caducidad ya acaecida no puede ser objeto de renuncia (a diferencia de la prescripción ya ganada, a la que puede renunciarse de modo expreso o tácito, por ser institución de derecho privado y de interés particular).

De acuerdo a las normas del Código Civil (“CC"), el plazo de caducidad, a diferencia del de prescripción, no se interrumpe en ningún caso, y solo puede suspenderse en un caso específicamente indicado por la ley ${ }^{10}$, que es mientras sea imposible reclamar el derecho ante un tribunal peruano, por cuanto se inspira en razones de orden público'11.

Así, mientras por regla general los términos de prescripción admiten suspensión ${ }^{12}$ y pueden ser interrumpidos ${ }^{13}$, los plazos de caducidad no comportan la posibilidad de ser ampliados por medio de la suspensión (salvo el único supuesto de excepción) ni interrumpidos, pues a priori, la caducidad simplemente ocurre. Por ello, a fin de evitar la caducidad (v.gr. la extinción) de la relación jurídica, solo cabe realizar el acto previsto por la ley (presentación de la demanda; de ser el caso,

9 MERINO, Roger. "Algunos apuntes en torno a la prescripción extintiva y la caducidad". En Dialogo con la Jurisprudencia. Lima: Gaceta Jurídica, N 104, 2007, p. 25.

10 Artículo 2005 Código Civil del Perú.- Continuidad de la caducidad

La caducidad no admite interrupción ni suspensión, salvo el caso previsto en el artículo 1994. inciso 8 .

11 Artículo 1994 del Código Civil del Perú.- Causales de suspensión de la prescripción

Se suspende la prescripción:

1.- Cuando los incapaces no están bajo la guarda de sus representantes legales.

2.- Entre los cónyuges, durante la vigencia de la sociedad de gananciales.

3.- Entre las personas comprendidas en el artículo 326.

4.- Entre los menores y sus padres o tutores durante la patria potestad o la tutela.

5.- Entre los incapaces y sus curadores, durante el ejercicio de la curatela.

6.- Durante el tiempo que transcurra entre la petición y el nombramiento del curador de bienes, en los casos que procede.

7.- Entre las personas jurídicas y sus administradores, mientras éstos continúen en el ejercicio del cargo.

8.- Mientras sea imposible reclamar el derecho ante un tribunal peruano.

12 Por ejemplo, el artículo 19 de la Ley de Conciliación (Ley 26872) contempla un caso de suspensión de los plazos de prescripción: cuando se presenta la solicitud de Conciliación Extrajudicial hasta la conclusión del proceso conciliatorio. Es así que, de tratarse de un plazo de caducidad, esta suspensión especial no opera.

13 Artículo 1996 del Código Civil del Perú.- Interrupción de la prescripción

Se interrumpe la prescripción por:

1.- Reconocimiento de la obligación.

2.- Intimación para constituir en mora al deudor.

3.- Citación con la demanda o por otro acto con el que se notifique al deudor, aun cuando se haya acudido a un juez o autoridad incompetente.

4.- Oponer judicialmente la compensación. 
iniciar el proceso arbitral; o el caso de la Ley General de Sociedades -Ley 26887-, en la que todos los plazos son de caducidad -a diferencia de antes, en que existían situaciones jurídicas sujetas a prescripción-; entre otros). Para en opinión de algunos, la notificación esta.

También, la caducidad opera contra todas las personas, sin miramiento sobre la calidad de los sujetos titulares del derecho, a diferencia de la prescripción, que bajo determinadas circunstancias no corre respecto a ciertas personas, en consideración de su calidad o incapacidad (art. 1994, incs. 1 al 7, del CC, antes citado).

En esta línea, es de resaltar que la prescripción es lo normal y corriente en cualquier derecho, pues casi todos son susceptibles de prescribir, en tanto que la caducidad afecta a algunos derechos determinados legal o convencionalmente. La caducidad es, por ende, un instituto excepcional, establecido de modo rígido por la ley y sus términos son, en general, más cortos que los de la prescripción, precisamente en atención al interés público que se busca salvaguardar.

Es por ello que, de advertirse que ha operado la caducidad -al verificar el hecho objetivo de la inactividad del interesado en el lapso consagrado en la ley para iniciar el proceso por la presentación de la demanda o reconvención-, debe procederse a declararla, así como también deberá declarar fundada la excepción de caducidad si ésta fuera propuesta, o, en todo caso, declararla en sentencia si antes no lo advirtió.

\section{Apreciación (¿actualización?) de la caducidad en supuestos específicos}

Por las características antes señaladas, se concluye que la caducidad es una institución de excepción, con supuestos específicos -jamás genéricos o con alcance extensivo-; se aplica a determinadas situaciones jurídicas cuya protección se acaba al cabo de cierto lapso temporal, pues en adelante se considera prioritaria la protección de otro interés.

Ahora bien, los alcances de esta institución han sido objeto de interpretaciones/actualizaciones, a fin de dotarlas de equilibrio (seguridad jurídica frente a los supuestos de la realidad que surgen y obligan a revisarla).

A continuación, es pertinente referirme a ciertos supuestos en los que la caducidad ha sido objeto de debate y actualización:

i. Por ejemplo, se ha debatido acerca de los supuestos en los que corresponde la aplicación de la suspensión de la caducidad (así como de la prescripción), cuando "sea imposible reclamar el derecho ante un tribunal peruano", siendo el caso más recurrente el de las huelgas judiciales:

Así, en la STC 04135-2011-PA/TC del 23 de abril de 2012, el Tribunal Constitucional señaló: 
“4. Que se aprecia de la resolución cuestionada, de fecha 27 de mayo de 2010, que en revisión declara infundada la excepción de caducidad propuesta, que esta se encuentra debidamente sustentada, al argumentarse que no puede contabilizarse para el plazo de caducidad establecido en el artículo $17^{\circ}$ de la Ley 27584 (ley que regula el proceso contencioso administrativo) los días de paralización del personal del Poder Judicial, toda vez que durante dicho período el recurrente no tuvo acceso al órgano de justicia por motivos ajenos a su actuar, criterio acorde con el pronunciamiento de la Sala Civil Transitoria de la Corte Suprema de Justicia de la República en la Apelación $\mathrm{N}^{\mathrm{o}} 218$-2003 Lima del 28 de octubre de 2003, que establece que el indicado hecho extraordinario supondría una causal de suspensión por imposibilidad del justiciable de reclamar su derecho ante un tribunal peruano, lo cual debe ser interpretado en concordancia con lo establecido por el artículo $1994^{\circ}$, inciso 8, y $2005^{\circ}$ del Código Civil".

Existen numerosas Casaciones en ese sentido, como por ejemplo la Casación 44082015-Lima:

“Octavo.- Estando a que, la parte demandante alega que se vio imposibilitada de interponer su demanda con anterioridad, por causa de la huelga nacional de los trabajadores del Poder Judicial, que se realizó los días 24 y 30 de octubre, 6, 7 y 13 de noviembre, y del 15 de noviembre al 5 de diciembre de 2012. Aspecto que determina la suspensión del cómputo del plazo de caducidad en aplicación del artículo $2005^{\circ}$ del Código Civil, en concordancia con el artículo $1994^{\circ}$ inciso 8) del mismo Código Sustantivo acotado, puesto que durante dicho período ésta se vio imposibilitada de reclamar el derecho ante un Tribunal Peruano. Criterio que coincide con lo señalado por el Tribunal Constitucional en la sentencia recaída en el Expediente $\mathrm{N}^{\circ}$ 04135-2011-PA/TC.

Undécimo.- Lo expuesto evidencia que las instancias de mérito se han limitado a aplicar el artículo $19^{\circ}$ inciso 1) del Texto Único Ordenado de la Ley $\mathrm{N}^{\circ} 27584$ de una manera que restringe el derecho a la tutela jurisdiccional de la entidad demandante, sin advertir que al regular el instituto de la caducidad, el Código Civil -aplicable supletoriamenteadmite como único supuesto de suspensión del cómputo de la caducidad, el invocado por la parte recurrente, esto es, la imposibilidad de acudir al órgano jurisdiccional, en este caso por paralización y huelga de los trabajadores del Poder Judicial, pues evidentemente no hubo Despacho Judicial".

ii. También se ha debatido acerca de si cuando el plazo vence una vez interpuesta la demanda pero sin haber sido aún notificada la parte demandada. Es de recordar que la normativa establece que el plazo se interrumpe, entre otros, con la citación con la demanda o por otro acto con el que se notifique al deudor (art. 1996.3 CC).

Al respecto, se realizó un Pleno Jurisdiccional Nacional Civil y Procesal los días 8 y 9 de julio del año 2016, en el que se abordó la siguiente interrogante: Prescripción de la acción: ¿En el caso de interposición de la demanda dentro del plazo legal 


\section{de prescripción, pero notificada luego de transcurrido el mismo, se produce o no la prescripción de la acción?}

Luego de expuestas las posiciones, se procedió al debate y se procedió a votar, adoptando por mayoría la siguiente postura: «En el caso de interposición de la demanda dentro del plazo prescriptorio que establece la ley, pero notificada después de trascurrido el mismo, no se produce la prescripción de la acción». Debe mencionarse que para muchos esta postura es de aplicación también para los casos de caducidad.

Obviamente, desde mucho antes de este Pleno Jurisdiccional (precisamente en razón de ello es que se llevó a cabo) este tema siempre ha sido objeto de diversas posturas y análisis.

Sobre el particular, Ariano opina que:

“[...] la propuesta -y la interpretación- de que sea la demanda la que interrumpa la prescripción no puede compartirse, pues ello implicaría desconocer el interés en juego en la prescripción: el del prescribiente, que ignorando la existencia de la demanda, puede haber alimentado la confianza de que el plazo de prescripción ya estaba vencido, ajustando así su comportamiento a tal situación. Pese a ello, en la Casación 2982-2010Huaura, del 30 de enero de 2012, así como en la Casación 774-2001-Huánuco, del 27 de enero de 2012, la Sala Civil Transitoria de la Corte Suprema ha considerado que la interrupción del decurso prescriptorio se produce con la interposición misma de la demanda y no con su notificación, pues "para que opere la prescripción extintiva tendría que considerarse el tiempo que tomará en notificar a la parte demandada (demoras del personal jurisdiccional), lo que evidentemente reduciría el plazo prescriptorio, lo que en cierto modo estaría afectando el ejercicio del derecho de acción, por tanto dichas restricciones no pueden tomarse en perjuicio del accionante". Quizá lo más sensato sería, sin alterar la ratio de la interrupción del plazo de prescripción, considerar que a partir de la presentación de la demanda el plazo se suspenda hasta la efectiva notificación al demandado, dado que ella está fuera de la esfera de control del demandante".

iii. Es interesante recordar, además, la posición de las Salas Comerciales respecto de los recursos de anulación, en el marco de los cuestionables arbitrajes que se llevaron a cabo a espaldas de los titulares de los derechos materia de proceso arbitral.

Es de conocimiento público que en estos casos, los laudos se "guardaron" un tiempo lo suficientemente prolongado para que venzan los plazos establecidos en la Ley de Arbitraje para interponer el recurso de anulación.

Una vez transcurrido tal plazo, se procedía a ejecutar el laudo, por ejemplo, inscribiéndose el derecho de propiedad en favor del vencedor en el arbitraje y/o procediendo al desalojo del ocupante. Fue así como muchos titulares de derechos se enteraron de lo ocurrido. Al interponer estos las demandas de anulación, explicando dichas circunstancias, se admitieron a trámite. Interpuestas las 
excepciones de caducidad correspondientes, estas fueron desestimadas, por cuanto se consideró que no cabía legitimar conductas ilegítimas de mala fe, y se realizó la interpretación dotando de contenido a la imposibilidad de reclamar ante tribunal peruano.

iv. Otro supuesto es el relativo a la anulación de laudo cuando se invoca como causal la revisión de lo resuelto en el arbitraje respecto de las excepciones, específicamente la excepción de caducidad.

Al respecto, la Corte Suprema (Casación 3079-2011-PIURA), señaló que el artículo 41.4 de la Ley de Arbitraje establece la posibilidad de acudir al recurso de anulación cuando se desestima una excepción contra la pretensión deducida en el proceso arbitral (cuestiones que no pertenecen al fondo de la controversia).

v. Respecto de la caducidad y las medidas cautelares fuera de proceso en el arbitraje, debe recordarse que la medida cautelar es una anticipación provisoria de los efectos de la decisión final, vista su instrumentalidad o preordenación (Calamandrei), cumple con un orden preventivo: evitar la especulación con la malicia (Couture). Al ser provisoria, la permanencia y duración de la medida cautelar dependen del proceso principal, cuya suerte seguirá aquélla.

Así, toda medida cautelar tiene carácter provisorio e instrumental, en virtud a lo cual la medida cautelar tiene determinada duración en el tiempo, y está destinada a proteger el derecho pretendido en la demanda (o que se pretenderá en el caso de la futura demanda). Por tanto, si esta última nunca es propuesta, la medida cautelar no debe continuar existiendo; es por ello que la norma procedimental (en las medidas cautelares fuera de proceso) ha establecido el plazo de diez días para el indicio del arbitraje (presentación de la solicitud arbitral ${ }^{14}$, lo que se equipara al plazo para la presentación de la demanda judicial), y el de 90 días en total desde el dictado de la medida cautelar hasta la constitución del Tribunal Arbitral ${ }^{15}$. Entonces, se aprecia que existen dos plazos: el de 10 días y el de 90 días ${ }^{16}$.

Sobre el plazo de 10 días para la presentación de la solicitud de sometimiento a arbitraje, debe señalarse que el mismo tiene una finalidad concreta: dado que la tutela cautelar supone una posible afectación a la futura otra parte (futura demandada), la normativa ha debido ponderar la necesidad de conceder tutela a la parte que asegura va a demandar (futura demandante) para que su alegado

14 Artículo 33 de la Ley de Arbitraje: "Inicio del arbitraje. Salvo acuerdo distinto de las partes, las actuaciones arbitrales respecto de una determinada controversia se iniciarán en la fecha de recepción de la solicitud para someter una controversia a arbitraje".

15 Artículo 27.2 de la Ley de Arbitraje: “Una vez producida la aceptación del árbitro único o del último de los árbitros, el tribunal arbitral se considerará válidamente constituido.

16 Artículo 47.4 de la Ley de Arbitraje: “Las medidas cautelares solicitadas a una autoridad judicial antes de la constitución del tribunal arbitral no son incompatibles con el arbitraje ni consideradas como una renuncia a él. Ejecutada la medida, la parte beneficiada deberá iniciar el arbitraje dentro de los diez (10) días siguientes, si no lo hubiere hecho con anterioridad. Si no lo hace dentro de este plazo o habiendo cumplido con hacerlo, no se constituye el tribunal arbitral dentro de los noventa (90) días de dictada la medida, ésta caduca de pleno derecho". 
derecho no se convierta en ilusorio, pero, al mismo tiempo, no puede conceder esta tutela de modo indefinido, más aun cuando no existe proceso aún en trámite, ni existe por tanto todavía parte demandada. Por ello, el plazo de 10 días sirve de freno a la posible mala fe del solicitante, pues se trata de un acto unilateral que dependerá exclusivamente de éste (quien es el beneficiado con la medida cautelar). Empero, en caso se presentase la circunstancia contenida en el artículo 1994.8 CC, este plazo podría suspenderse. Si bien podría considerarse difícil imaginar algún supuesto, ello no significa que no podría ocurrir un caso de imposibilidad material, irresistible, de solicitar el sometimiento a arbitraje a la otra parte (por ejemplo, si se ha pactado arbitraje institucional, con institución arbitral definida en el convenio, y dicha institución ha cerrado temporalmente por motivos de fuerza mayor, etc.).

Por su parte, el plazo de 90 días para la constitución del Tribunal Arbitral. Esto podría ser más complicado, por cuanto ya no involucra necesariamente la voluntad de la parte solicitante, pues requiere de la intervención de la otra parte, de que ésta nombre a su árbitro, de que ambos árbitros se pongan de acuerdo en nombrar al presidente del Tribunal, de la falta de acuerdo en ese sentido, de la demora por parte de la Institución en nombrar al presidente, etc. Es por ello que la norma ha establecido un plazo amplio, que a no dudar es razonable.

Entonces, se trata de un plazo máximo que la ley concede a quien ha obtenido una medida cautelar fuera de proceso para que se constituya el tribunal arbitral y demuestre así que el pedido cautelar obedecía realmente a una necesidad de tutela seria y no a la obtención de un beneficio que no merecía.

Ahora bien, si la caducidad tiene como telón de fondo la falta de manifestación de voluntad destinada a hacer valer un derecho en forma legal oportuna, y si el solicitante lo ha realizado en forma diligente (pasó la valla de los 10 días), y el resto del plazo (supuesto extremo, sin duda) ha sido empleado por la contraparte y por la Institución Arbitral, sin que hubiese habido falta de diligencia por el solicitante en acatar los plazos y disposiciones de la normativa, ¿cabría que se aplique a este una "sanción" que derribe su derecho reconocido (de obtener una medida cautelar), debido a hechos de terceros?

En efecto, si en lo relativo a medidas cautelares los efectos de la caducidad recaen en la medida cautelar concedida y no en el derecho sustantivo de la parte (pudiendo volverse a plantear la misma solicitud de medida cautelar y ésta fuera concedida si se mantienen los mismos presupuestos y elementos) a diferencia del concepto general de caducidad (que extingue la relación sustantiva), ¿no sería entonces acaso factible que pudiese solicitar al Tribunal Arbitral ya constituido que declare que la medida cautelar no caducó, si acreditase que no le fue imputable la demora en la constitución del Tribunal? ¿no le sería extensible el supuesto de suspensión por "imposibilidad de reclamar el derecho ante tribunal peruano"?, ¿no se habría configurado un supuesto de abuso del derecho por parte del futuro demandado? 
vi. Finalmente, resulta interesante el recuento de un caso ocurrido en el marco de un arbitraje. Denominaré A a la parte demandante (empresa privada) y B a la parte demandada (entidad estatal).

La secuencia de actos realizados por las partes y por el Tribunal Arbitral fue la siguiente:

a. A resolvió el Contrato que lo vinculaba a B.

b. B solicitó el inicio de un proceso arbitral ad hoc por medio de la carta xx.

c. A presentó un escrito a un Centro Arbitral, con sumilla "interpone demanda arbitral", con la reserva de su derecho a formular sus pretensiones y fundamentos, así como designando a su árbitro.

d. A contestó la solicitud de arbitraje oponiéndose a que el arbitraje sea ad hoc y señalando que debía ser institucional y adjuntó el escrito referido en el punto anterior.

e. A presentó al Centro Arbitral un escrito, con sumilla "interpone petición arbitral", solicitando el inicio del presente arbitraje contra B.

f. B presentó al Centro Arbitral un escrito, con sumilla "contestamos petición arbitral" y oponiéndose al arbitraje iniciado por A.

g. El Consejo Superior de Arbitraje resolvió la oposición al arbitraje formulada por B, decidiendo que el arbitraje debía continuar y que sería el Tribunal Arbitral que se constituya el que se pronuncie sobre su propia competencia.

h. El Tribunal Arbitral dictó el proyecto de reglas del proceso, otorgando a las partes un plazo de cinco (5) días hábiles para que expresen sus observaciones. Posteriormente fijó las reglas definitivas del proceso, y otorgó a A el plazo para que presente su demanda arbitral.

i. A presentó su escrito de demanda, y después B presentó su escrito de contestación de demanda y formuló reconvención.

j. A planteó excepción de caducidad, alegando que la reconvención equivale a la demanda de $\mathbf{B}$, habiendo ya caducado el plazo para ello (entre la resolución del Contrato y el inicio del medio de solución de controversias).

El Tribunal tomó en consideración que, de acuerdo a varios artículos del reglamento aplicable a dicho caso, el requisito para que el arbitraje sea considerado institucional era que la institución arbitral debía encontrarse debidamente acreditada ante el OSCE, debiendo las partes encomendar la organización y administración del arbitraje a una institución arbitral debidamente acreditada ante el OSCE, estableciéndose inclusive un mecanismo para su elección. El reglamento dejaba en claro que si la institución arbitral no estaba registrada o perdía su registro dejaba de ser considerada como tal. 
El Tribunal Arbitral razonó que si las instituciones arbitrales no se encontraban registradas podrían considerarse al mismo nivel que el arbitraje tramitado bajo la modalidad ad hoc, preguntándose qué ocurría si no se registraron instituciones arbitrales ante el OSCE, y respondiéndose que de ninguna manera podría considerarse que las controversias quedaban sin solución heterocompositiva (solo quedaría la conciliación), considerando además que la normativa establece jurisdicción arbitral y no Judicial. Se concluyó que ello no era acorde al espíritu de la norma sobre contratación pública ni sobre arbitraje, ni tampoco tal interpretación podía ser constitucional; si la norma exigía una institucionalidad que no existe en la realidad, entonces debe acudirse a los principios básicos, que son el acceso a la jurisdicción, el derecho de acudir a un medio idóneo heterocompositivo de solución de controversias, el derecho de defensa, entre otros.

En esa línea, se optaba por una interpretación extensiva de derecho, y así concluyó que era absolutamente razonable acudir al arbitraje en general, sea ad hoc o sea ante un centro arbitral no registrado ni acreditado ante el OSCE. Reflexionó que quizá podría suponerse que una institución no acreditada ante el OSCE valía más que el arbitraje ad hoc (que la norma no deseaba salvo para determinados supuestos de controversias), pero que esta distinción -además de subjetiva- no estaba realizada por la normativa y, además, que si la idea era la supervisión por parte del OSCE, tan no supervisada y/o aprobada estaba una institución que no tenía la aprobación ni supervisión de OSCE como una organización pequeña -de un tribunal arbitral con su secretaría ad hoc-. En ambos casos estaban igualmente no aprobadas/acreditadas/supervisadas por el OSCE. Por lo demás, señaló que las distinciones o preferencias entre una y otra no competían al Tribunal.

Bajo esa óptica, se razonó que no cabía considerar que la única que había presentado una solicitud de arbitraje había sido A y que la solicitud presentada por B no había existido o era nula, y que ambas partes habían planteado solicitudes arbitrales (B antes que A), siendo que A lo había hecho ante el Centro Arbitral y B en forma directa a su contraparte, al optar por el arbitraje ad hoc; ninguna cumplía con lo establecido en el reglamento, y al no haber opciones viables, no cabía tampoco considerarse que en ambos casos las solicitudes carecieron de existencia y/o viabilidad jurídica. En ese sentido, el Tribunal Arbitral concluyó que al haber presentado B su solicitud de arbitraje a la contraparte dentro del plazo establecido, la caducidad dejó de correr y ya no operó; su conducta al oponerse al arbitraje que luego inició A, así como su defensa frente a la oposición de A, revelaban consistencia respecto de su voluntad y actos conducentes a acudir en tiempo oportuno a presentar sus pretensiones y ejercer su derecho. La solicitud de arbitraje de A, así como las mutuas oposiciones a los arbitrajes iniciados por las respectivas contrapartes, generaron duplicidad de inicios arbitrales cruzados, decantándose finalmente por ser tramitado y administrado ante el Centro Arbitral y no ante una secretaría ad hoc. En ese marco de actuaciones, voluntad y de conformidad al básico de la buena fe, este Tribunal Arbitral consideró irrelevante que B hubiese optado por ejercer ese derecho (al que nunca renunció y por el que 
en forma consistente había venido enfrentando a su contraparte contractual), dentro de una demanda o dentro de una reconvención.

La breve revisión de estos supuestos permite apreciar que el derecho vive en perpetua construcción y actualización. El equilibrio entre la necesaria seguridad jurídica (finalidad de la institución de la caducidad) y su racionalidad en la realidad debe permitir el ordenado juego de intereses individuales como de intereses sociales. 